\title{
How to evaluate a patient's response
}

\section{to anti-lgE}

\author{
S.T. Holgate
}

\begin{abstract}
Omalizumab, an anti-immunoglobulin E antibody, is indicated in the European Union (EU) as add-on therapy for patients with severe persistent allergic asthma whose symptoms persist, despite receiving optimised treatment with high-dose inhaled corticosteroids and a longacting $\beta_{2}$-agonist. In an attempt to further optimise the use of omalizumab, studies have been performed to investigate whether patient selection for omalizumab therapy could be further enhanced.
\end{abstract}

Analyses of pre-treatment baseline variables have shown there is no reliable way to predict which patients within the label population will achieve a greater response to omalizumab. However, a physician's overall assessment can easily and reliably identify patients who respond to omalizumab. All patients eligible for omalizumab treatment should receive a 16-week trial and treatment should only be continued if the physician judges that a marked improvement in asthma control has been achieved, as specified in the EU label.

By continuing treatment only in patients who respond to omalizumab therapy, unwarranted drug exposure is minimised, while treatment benefit and cost effectiveness of the therapy are maximised.

\section{KEYWORDS: Allergic asthma, anti-immunoglobulin E, omalizumab}

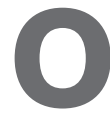
malizumab is an anti-immunoglobulin (Ig)E antibody and is indicated in the European Union (EU) as add-on therapy for patients with severe persistent allergic asthma whose symptoms persist, despite receiving optimised treatment with high-dose inhaled corticosteroids (ICS) and a long-acting $\beta_{2}$-agonist (LABA). It has proven efficacy in moderate-tosevere and severe persistent allergic asthma [110], and is indicated for the treatment of a highly targeted population.

In an attempt to further optimise the use of healthcare resources, studies have been performed in order to investigate whether patient selection for omalizumab therapy could be further enhanced [11]. Data from clinical trials have been analysed to investigate if patients who achieve greatest benefits from treatment with omalizumab can be identified based on pretreatment characteristics [11]. The best method for identifying patients who respond to omalizumab following a course of therapy has also been determined [11].

\section{OVERVIEW OF CLINICAL TRIALS}

Post hoc analyses were carried out on five randomised, double-blind, placebo-controlled studies [1, 3, 4-8], including the Investigation of
Omalizumab in Severe Asthma Treatment (INNOVATE) trial, and two randomised, controlled open-label studies [2, 9]. In all studies, omalizumab was given as add-on therapy to concomitant asthma treatment and administered subcutaneously every 2 or 4 weeks, according to patients' pre-treatment body weight and baseline IgE levels by use of a dosing table. All trials were $\geqslant 24$ weeks in duration ( 28 weeks for INNOVATE) and enrolled patients with allergic asthma. Patients enrolled in the INNOVATE study [1] had inadequately controlled severe persistent allergic asthma, despite Global Initiative for Asthma (GINA) 2002 step 4 therapy (high-dose ICS and a LABA, with or without additional controller medication). Of these patients, $\sim 60 \%$ were receiving additional controller medication (including maintenance oral corticosteroids $(22 \%)$, leukotriene modifiers $(35 \%)$ and theophyllines $(27 \%))$, which was optimised prior to the 28-week treatment phase. Overall, $93 \%$ of patients (aged $\geqslant 12$ yrs) across the seven studies met GINA 2002 criteria for severe persistent asthma [10].

\section{PREDICTING RESPONSE}

Initial exploratory univariate and multivariate analyses of data from the INNOVATE study were conducted based on eight response measures and
CORRESPONDENCE

S.T. Holgate

Southampton General Hospita

RCMB Division

Mailpoint 810

Level D

Centre Block

Southampton S016 6YD

UK

Fax: 442380701771

E-mail: sth@soton.ac.uk

\section{STATEMENT OF INTEREST}

S.T. Holgate has received payment for chairing an advisory board for Novartis Pharma AG, has been reimbursed for attending a conference in the USA (AAAAI) and also for speaking, and is in receipt of a research grant from Novartis Pharma AG. This issue of the European Respiratory Review contains proceedings of a satellite symposium held at the 16th ERS Annual Congress, 2006, which was sponsored by Novartis Pharma AG. The authors were assisted in the preparation of the text by professional medical writers at $\operatorname{ACUMED}_{\mathbb{R}}$; this support was funded by Novartis Pharma AG. 
29 baseline variables (table 1). Those baseline variables that demonstrated a significant interaction with treatment response after univariate analyses of the INNOVATE data were included in the multivariate analyses, which evaluated the predictive value of combinations of baseline variables for each response measure. Baseline total IgE was the only characteristic identified as a consistent predictor of response in the univariate and multivariate analyses, with lower baseline IgE being associated with a smaller treatment benefit. However, this finding was only partially supported after further investigation in exploratory efficacy subgroup analysis of data from the larger pooled population from all seven trials [1-9]. Pooled data from all seven studies was used to obtain sufficient patient numbers over a wide range of $\mathrm{IgE}$ levels, and subgroup analysis was conducted within four quartiles based on baseline total $\operatorname{IgE}(0-75,76-147$, 148-273 and $\left.\geqslant 274 \mathrm{IU} \cdot \mathrm{mL}^{-1}\right)$. Outcome variables assessed according to baseline total $\mathrm{IgE}$ are shown in table 1 .

Pooled analyses showed treatment benefit irrespective of baseline IgE. In the omalizumab-treated patients, the asthma exacerbation rate was reduced across all IgE levels, reaching statistically significant decreases in each of the three upper $\operatorname{IgE}$ quartiles (table 2; fig. 1). Severe exacerbation rates decreased across all four quartiles in omalizumab-treated patients, with statistically significant differences in quartiles 1, 3 and 4 . Total emergency visit rates were significantly reduced for the three upper quartiles. The proportion of patients with a clinically meaningful Asthma Quality of Life Questionnaire (AQLQ) improvement and forced expiratory volume in one second (FEV1) net benefit favoured omalizumab-treated patients in the three upper $\operatorname{IgE}$ quartiles. Significant improvements in physician's overall assessment (complete control/marked improvement in asthma control) were seen in all IgE quartiles (table 2). A comparison of patients with $\operatorname{IgE} \leqslant 75$ and patients with $\mathrm{IgE} \geqslant 76 \mathrm{IU} \cdot \mathrm{mL}^{-1}$ produced similar results (table 3 ).

Exacerbation rates in the control group were similar across all IgE levels (table 2; fig. 1), which demonstrates a medical need irrespective of baseline $\operatorname{IgE}$ and also highlights a poor correlation between total IgE and disease severity. As such, baseline patient characteristics do not robustly predict treatment response. Further studies are currently ongoing to investigate the potential predictive value of other biomarkers, including baseline levels of specific $\operatorname{IgE}$ (particularly in patients with serum $\left.\mathrm{IgE} \leqslant 75 \mathrm{IU} \cdot \mathrm{mL}^{-1}\right)$, pharmacogenetics $(40$ single nucleotide polymorphisms associated with the highaffinity receptor) and blood markers (IgE-mediated inflammatory pathways).

\section{EVALUATING RESPONSE}

Analyses consisting of four main steps were conducted on efficacy results from the INNOVATE study [1] and the four additional randomised, double-blind, placebo-controlled trials [2, 4-8].

\section{Step 1}

Step 1 was the identification of an effective and accurate measure of response to omalizumab that could select responders who achieved control in terms of exacerbations.

Six measures of response were assessed (table 4), including a physician's overall assessment of asthma control, graded in a five-level evaluation: complete control; marked improvement in control; discernible but limited control; no appreciable change; and worsening in control. Responders were defined as

\section{TABLE 1 Assessment of pre-treatment baseline measures}

\section{Univariate analysis}

Response measures

Number, incidence and rate of clinically significant asthma exacerbations (worsening of asthma requiring systemic corticosteroids)

Number and incidence of severe exacerbations (PEF or FEV $1<60 \%$ of personal best and requiring treatment with systemic corticosteroids)

Asthma-related QoL (\% patients with $\geqslant 0.5$-point increase in total AQLQ score) $[12,13]$

Physician's overall assessment (\% patients judged to have complete control of asthma or marked improvement) [4]

Lung function (\% patients with $\geqslant 200-\mathrm{mL}$ improvement in FEV1) [14]

Baseline variables

Overall AQLQ score; ICS; oral corticosteroids used; GINA clinical features; mould allergy; exacerbations in the previous year; sex; age; weight; height; smoker; IgE; \% pred FEV1; duration of asthma; number of positive allergens; qualifying FEV1 reversibility; in hospital during previous year; ever intubated; emergency room during previous year; doctor during previous year; missed school/work during previous year; nocturnal symptom score; daytime symptom score; total symptom score; morning symptom score; morning PEF; rescue medication use; schedule; time since previous exacerbation

\section{Pooled efficacy subgroup analysis}

Asthma exacerbation rate ${ }^{\#}$

Severe exacerbation rate (PEF or FEV1 $<60 \%$ or $<50 \%$ (study dependent) of personal best and requiring treatment with systemic corticosteroids)

Total emergency visit rate (hospital admissions, emergency room visits and unscheduled doctor visits)

FEV1 clinically meaningful net benefit (\% patients with $\geqslant 200-\mathrm{mL}$ improvement in FEV1 minus \% patients with a $\geqslant 200-\mathrm{mL}$ worsening) [14]

$\geqslant 0.5$-point increase in overall AQLQ score $[12,13]$

Physician's overall assessment (complete control of asthma or marked improvement) [6]

PEF: peak expiratory flow; FEV1: forced expiratory volume in one second; QoL: quality of life; AQLQ: Asthma Quality of Life Questionnaire; ICS: inhaled corticosteroids GINA: Global Initiative for Asthma; Ig: immunoglobulin. ${ }^{\#}$ : defined as a worsening of asthma requiring systemic corticosteroids in three studies $[1,2,8]$ and as worsening of asthma requiring systemic corticosteroids or doubling of ICS doses in three studies [3-7] ( $\sim 90 \%$ of events required systemic corticosteroids). One study [9] defined exacerbations as a worsening of asthma requiring systemic corticosteroids or a doubling of ICS in addition to an emergency room visit or hospitalisation ( $94 \%$ of exacerbations were treated with systemic corticosteroids). Data taken from [11]. 


\begin{tabular}{|c|c|c|c|c|c|c|c|c|}
\hline \multirow[t]{2}{*}{ Outcome measure } & \multicolumn{8}{|c|}{ Baseline IgE subgroup } \\
\hline & Omalizumab & Control & Omalizuma & Control & Omalizuma & Control & Omalizuma & Control \\
\hline $\begin{array}{l}\text { exacerbation rate } \\
\% \text { decrease }^{\#}\end{array}$ & \multicolumn{2}{|c|}{13.8} & \multicolumn{2}{|c|}{41.9} & \multicolumn{2}{|c|}{45.4} & \multicolumn{2}{|c|}{46.5} \\
\hline p-value & \multicolumn{2}{|c|}{0.227} & \multicolumn{2}{|c|}{$<0.001$} & \multicolumn{2}{|c|}{$<0.001$} & \multicolumn{2}{|c|}{$<0.001$} \\
\hline $\begin{array}{l}\text { Annualised severe } \\
\text { exacerbation rate }\end{array}$ & 0.09 & 0.22 & 0.07 & 0.11 & 0.07 & 0.20 & 0.05 & 0.17 \\
\hline$\%$ decrease ${ }^{\#}$ & \multicolumn{2}{|c|}{31.0} & \multicolumn{2}{|c|}{46.3} & \multicolumn{2}{|c|}{60.9} & \multicolumn{2}{|c|}{40.8} \\
\hline$p$-value & \multicolumn{2}{|c|}{0.141} & \multicolumn{2}{|c|}{$<0.05$} & \multicolumn{2}{|c|}{$<0.01$} & \multicolumn{2}{|c|}{$<0.05$} \\
\hline FEV1 net benefit \% & 4.1 & -0.5 & 11.7 & 3.4 & 7.9 & 0.5 & 22.3 & 2.9 \\
\hline p-value & 0.2 & & & & & & & \\
\hline $\begin{array}{l}\text { AQLQ improvement } \geqslant 0.5 \\
\text { points } \%\end{array}$ & 58.7 & 54.2 & 67.5 & 54.0 & 68.7 & 50.0 & 68.9 & 52.5 \\
\hline p-value & 0.2 & & & & & & & \\
\hline $\begin{array}{l}\text { Physician's overall } \\
\text { assessment } \%\end{array}$ & 49.3 & 40.2 & 59.3 & 42.9 & 66.6 & 36.1 & 67.1 & 36.2 \\
\hline p-value & $<0$ & & & & & & & \\
\hline
\end{tabular}

FEV1: forced expiratory volume in one second; AQLQ: Asthma Quality of Life Questionnaire. ${ }^{\#}$ : in rate in omalizumab patients compared with control. Data taken from [11].

those with marked improvement or complete control. All response measures evaluated (with the exception of FEV1 improvements) were able to discriminate exacerbation outcome. Responders identified by physician's overall assessment and AQLQ (response defined as $\geqslant 0.5$-point improvement) had

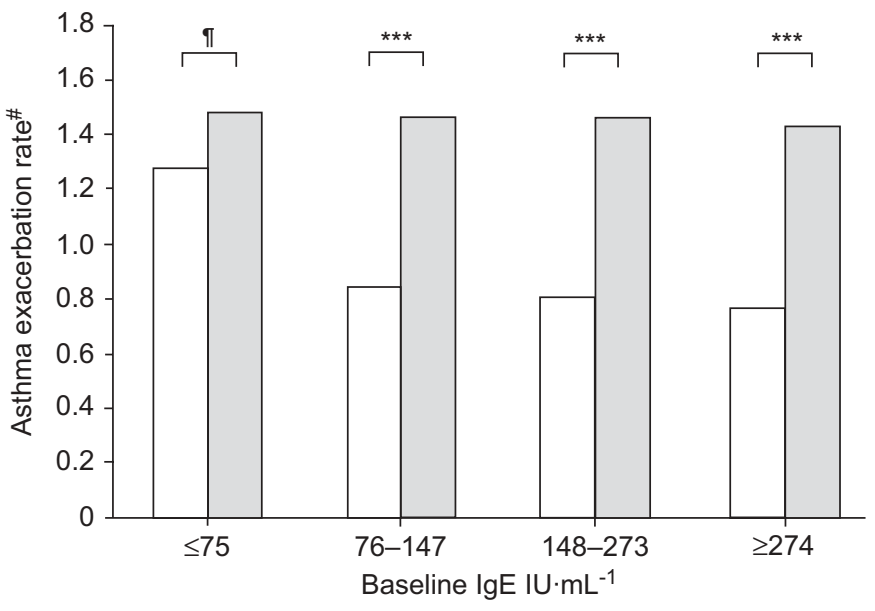

FIGURE 1. Annualised asthma exacerbation rates in patients according to baseline immunoglobulin (Ig)E (pooled population). $\square$ : omalizumab-treated patients; a: controls. *: annualised; ": $p=0.227$; ***: $p<0.001$. Data taken from [11]. markedly fewer clinically significant exacerbations than nonresponders (table 5). Both measures were able to identify a greater proportion of responders compared with single-item measures while maintaining a similar discrimination for exacerbation outcomes.

A large proportion of omalizumab patients identified as responders according to the broader measures of response were also classed as responders by single-item response measures (FEV1, daytime symptoms, nocturnal symptoms and night awakenings). However, responders according to single-item measures were not necessarily identified by other single-item or broader measures of response. Using single item measures to assess response to omalizumab was, therefore, not considered to be appropriate as these would lead to false negative results.

Further examination of the broader measures showed that the physician's overall assessment was able to discriminate for severe asthma exacerbations; however, according to AQLQ, the severe exacerbation rate was similar in both responders and nonresponders. Therefore, the physician's overall assessment was selected as the best definition of response. Similar data were observed in the pooled population.

\section{Step 2}

Step 2 consisted of the determination, according to the physician's overall assessment, of whether responders also 


\begin{tabular}{|c|c|c|c|}
\hline TABLE 3 & \multicolumn{3}{|c|}{$\begin{array}{l}\text { Pooled baseline immunoglobulin (Ig)E subgroup } \\
\text { analysis }\end{array}$} \\
\hline \multirow{2}{*}{\multicolumn{2}{|c|}{$\begin{array}{l}\text { Efficacy outcome } \\
\text { omalizumab versus control }\end{array}$}} & \multicolumn{2}{|c|}{ Baseline IgE subgroup } \\
\hline & & $\leqslant 75 \mathrm{IU} \cdot \mathrm{mL}^{-1}$ & $\geqslant 76 \mathrm{IU} \cdot \mathrm{mL}^{-1}$ \\
\hline $\begin{array}{l}\text { Clinically sig } \\
\text { rate }\end{array}$ & ificant exacerbation & $-13.8 \%$ & $-46.8 \%$ \\
\hline Severe exac & rbation rate & $-59.7 \%$ & $-55.7 \%$ \\
\hline Total emerge & ncy visit rate & $-31.0 \%$ & $-48.5 \%$ \\
\hline $\begin{array}{r}\text { Physician's } \\
\% \text { of respo }\end{array}$ & $\begin{array}{l}\text { verall assessment } \\
\text { nders }\end{array}$ & 49.3 versus 40.2 & 64.5 versus 38.2 \\
\hline $\begin{array}{r}\geqslant 0.5 \text { improv } \\
\text { score } \% \text { of }\end{array}$ & $\begin{array}{l}\text { ment in AQLQ } \\
\text { patients }\end{array}$ & 58.7 versus 54.2 & 68.4 versus 52.7 \\
\hline
\end{tabular}

showed improvements across a range of other measures of asthma control.

Patients identified as responders according to the physician's overall assessment had greater benefits for all clinical outcomes (healthcare utilisation, symptoms, rescue medication use, FEV1 and asthma-related quality of life (QoL)) in both INNOVATE (table 6) and the pooled populations, with marked improvements in asthma control and healthcare utilisation. Physician's overall assessment was shown to be sensitive to patients' perceptions of improved QoL, as indicated by the correlation with AQLQ score. Similar data were observed in the pooled population.

\section{Step 3}

Step 3 was a utility analysis to identify objective clinical measures (including combinations of measures) that could identify responders to the physician's overall assessment.

\section{TABLE 4 Methods for evaluating response}

Responder definitions assessed for evaluating response to omalizumab

Physician's overall assessment (complete control of asthma or marked improvement) ${ }^{\#}[4]$

$\geqslant 0.5$-point improvement in AQLQ overall score $[12,13]$

$\geqslant 200-\mathrm{mL}$ improvement in FEV 1 [14]

$\geqslant 1.0$-point reduction in daytime symptom score (4-point scale

0: no symptoms; 4: major discomfort) [6]

$\geqslant 1$.0-point reduction in nocturnal symptom score (4-point scale;

0: no symptoms; 4: major discomfort) [6]

Reduction $\geqslant 1 \cdot$ week $^{-1}$ and by $\geqslant 50 \%$ in night awakenings

AQLQ: Asthma Quality of Life Questionnaire; FEV1: forced expiratory volume in one second. * : five-level evaluation (complete control; marked improvement in control; discernible but limited control; no appreciable change; and worsening in control). Data taken from [11].

No single response measure (out of more than 50 tested) or combination of measures had a meaningful level of both sensitivity (proportion of true-positive response that has a positive test result) and specificity (proportion of true-negative response that has a negative test result) for detecting physician's overall assessment responders.

\section{Step 4}

Step 4 was a comparison of exacerbation rates in omalizumabtreated patients who were responders according to the physician's overall assessment and in an omalizumab-treated patient population with total baseline $\mathrm{IgE} \geqslant 76 \mathrm{IU} \cdot \mathrm{mL}^{-1}$.

Rate ratios (omalizumab/placebo) for exacerbation rates for omalizumab-treated responders and for omalizumab-treated patients with total baseline $\mathrm{IgE} \geqslant 76 \mathrm{IU} \cdot \mathrm{mL}^{-1}$ were calculated. The reduction in asthma exacerbation rates versus placebo was greater in responders than in the overall omalizumab-treated

TABLE 5 Annualised clinically significant exacerbation rates according to various responder definitions

Response measure
Clinically significant exacerbations

\begin{tabular}{|c|c|c|c|}
\hline \multicolumn{2}{|c|}{ Responder } & \multicolumn{2}{|c|}{ Nonresponder } \\
\hline n (\%) & Rate & $\mathbf{n}$ & Rate \\
\hline
\end{tabular}

\section{Physician's overall assessment}

Complete control or marked improvement

$A Q L Q \geqslant 0.5$ improvement

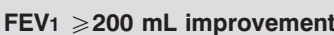

Symptom score $\geqslant 1.0$ reduction

Daytime

Nocturnal

Night awakenings reduced by $\geqslant 1 \cdot$ week $^{-1}$ and $\geqslant 50 \%$

$\begin{array}{lccc}118(61) & 0.6 \pm 1.31 & 77 & 2.6 \pm 6.39 \\ 124(61) & 0.8 \pm 1.45 & 80 & 1.7 \pm 2.90 \\ 90(44) & 1.2 \pm 2.39 & 116 & 1.1 \pm 2.00 \\ 36(21) & & & \\ 32(18) & 0.3 \pm 0.83 & 140 & 1.7 \pm 4.96 \\ 57(32) & 0.4 \pm 0.87 & 146 & 1.6 \pm 4.87 \\ & 0.8 \pm 2.13 & 121 & 1.7 \pm 5.18\end{array}$

Data are presented as mean \pm SD, unless otherwise stated. AQLQ: Asthma Quality of Life Questionnaire; FEV1: forced expiratory volume in one second. Imputed exacerbations resulted in some patients with high exacerbation rates not being included in all analysis populations. Therefore, to enable meaningful direct comparisons all exacerbation rates are presented without imputation. Clinically significant exacerbations were defined as a worsening of asthma requiring treatment with systemic corticosteroids. Data taken from [11] 


\begin{tabular}{|c|c|c|c|}
\hline \multirow[t]{2}{*}{ TABLE 6} & \multicolumn{3}{|c|}{$\begin{array}{l}\text { Annualised exacerbation rates, unscheduled } \\
\text { healthcare utilisation and other asthma control } \\
\text { measures according to physician's overall } \\
\text { assessment for responders and nonresponders } \\
\text { to omalizumab (INNOVATE study) }\end{array}$} \\
\hline & & Responder & Nonresponder \\
\hline \multicolumn{2}{|c|}{ Clinically significant exacerbations rate } & $0.6 \pm 1.31$ & $2.6 \pm 6.39$ \\
\hline \multicolumn{2}{|c|}{ Severe exacerbations rate } & $0.2 \pm 0.6$ & $1.4 \pm 6.1$ \\
\hline \multicolumn{4}{|c|}{ Hospitalisations ${ }^{\#}$} \\
\hline \multicolumn{2}{|c|}{ Patients hospitalised in treatment phase $\%$} & 2.5 & 9.1 \\
\hline \multicolumn{2}{|l|}{ Rate } & $0.03 \pm 0.22$ & $0.10 \pm 0.35$ \\
\hline \multicolumn{2}{|c|}{ Emergency room visits ${ }^{\#}$ rate } & $0.02 \pm 0.17$ & $0.17 \pm 0.80$ \\
\hline \multicolumn{2}{|c|}{ Unscheduled physician visits ${ }^{\#}$ rate } & $0.11 \pm 0.44$ & $0.49 \pm 1.31$ \\
\hline \multicolumn{2}{|c|}{ Any unscheduled healthcare utilisation rate } & $0.20 \pm 0.61$ & $1.50 \pm 6.14$ \\
\hline \multicolumn{2}{|c|}{ Asthma symptom score } & $-1.24 \pm 1.82$ & $-0.47 \pm 1.72$ \\
\hline \multicolumn{2}{|c|}{ Night awakenings due to asthma per week } & $-1.23 \pm 2.22$ & $-0.28 \pm 2.74$ \\
\hline \multicolumn{2}{|c|}{ Daily rescue medication use puffs" } & $-2.32 \pm 3.93$ & $-0.17 \pm 3.79$ \\
\hline \multicolumn{2}{|l|}{ FEV $1 \mathrm{~mL}^{*}$} & $252 \pm 521$ & $87 \pm 445$ \\
\hline \multicolumn{2}{|c|}{$\begin{array}{l}\text { AQLQ improvement } \geqslant 0.5 \text { points } \% \text { of } \\
\text { patients }\end{array}$} & 78.8 & 34.7 \\
\hline
\end{tabular}

Data are presented as mean $\pm \mathrm{SD}$, unless otherwise stated. INNOVATE: Investigation of Omalizumab in Severe Asthma Treatment; FEV1: forced expiratory volume in one second; AQLQ: Asthma Quality of Life Questionnaire. ${ }^{*}$ : rates in the previous year were similar for responders and nonresponders; ${ }^{\bullet}$ : values correspond to changes from baseline. Data taken from [11].

population and was observed irrespective of baseline IgE (figs $2 a$ and $2 b$ ). These data provide further evidence of the limitations of selecting a subpopulation of patients based on total baseline IgE within the range specified for omalizumab therapy $\left(30-700 \mathrm{IU} \cdot \mathrm{mL}^{-1}\right)$.

In summary, the physician's overall assessment was able to identify responders and discriminate clinically significant and severe exacerbation outcomes and other outcomes in responders versus nonresponders, and was also able to identify a high proportion of patients classified as responders by other measures. In addition, the improvements in clinically significant and severe exacerbation rates were similar in responders irrespective of baseline total $\mathrm{IgE}$.

\section{TIME TO MAXIMAL THERAPEUTIC BENEFIT}

For maximum therapeutic benefit, complete desensitisation of the allergic response is needed. Minimisation of cell-bound, cross-linked IgE/allergen complexes on effector cells is achieved through two mechanisms that occur at different rates: 1) binding to circulating free serum $\mathrm{IgE}$ rendering it inactive, which occurs within days; and 2) the downregulation of high-affinity cell surface IgE receptor (FceRI) expression, which takes weeks to months, depending on the effector cell type [16-18]. For example, omalizumab reduces FceRI levels on circulating basophils by $>90 \%$ in 7 days, whereas FceRI expression on mast cells remains stable over the first 7 days and is reduced by $90 \%$ at 70 days [17]. Based on cell desensitisation data, a minimum treatment of 12 weeks is a)

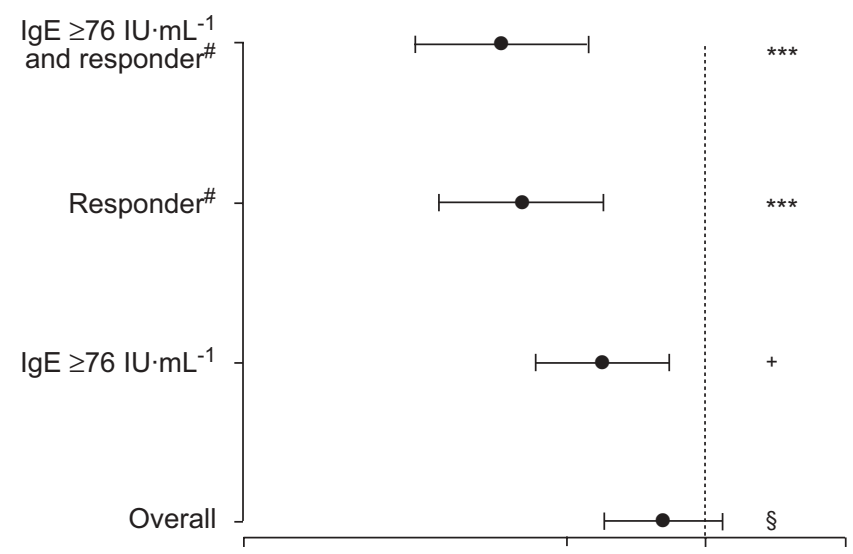

b)

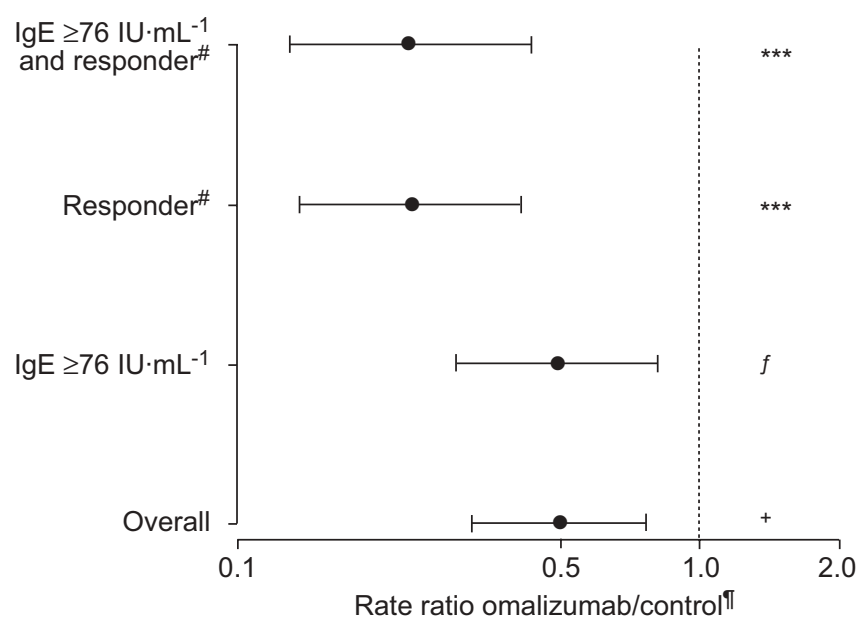

FIGURE 2. Relative rates of a) clinically meaningful exacerbations and b) severe exacerbations in patients with baseline immunoglobulin $(\mathrm{Ig}) \mathrm{E} \geqslant 76 \mathrm{IU} \cdot \mathrm{mL}^{-1}$, physician's overall assessment responders, patients with both of these criteria and the overall omalizumab-treated population (Investigation of Omalizumab in Severe Asthma Treatment (INNOVATE) study). Data are shown as rate ratios (omalizumab/ placebo) calculated using the Poisson regression model. Error bars represent 95\% confidence intervals. \#: complete/marked improvement according to the physician's overall assessment; " : logarithmic scale. ${ }^{* * *}: p<0.001 ;{ }^{+}: p=0.002$; s: $p=0.156 ;{ }^{f}: p=0.008$. Reproduced from [11] with permission from the publisher

needed prior to evaluation of clinical benefit. Data from the INNOVATE study [1] shows a plateau of improvement in asthma symptoms and morning peak expiratory flow around 12-16 weeks (fig. 3), reflecting the downregulation of FceRI receptors on effector cells.

Therefore, the omalizumab EU label states that 16 weeks after commencing therapy patients should be assessed by their physician for treatment effectiveness before further injections are administered. The decision to continue omalizumab therapy should be based on whether a marked improvement in overall asthma control is seen. When implementing a 16week assessment in clinical practice, the physician should define key treatment goals for each patient, including improvements in symptoms, lung function and use of 

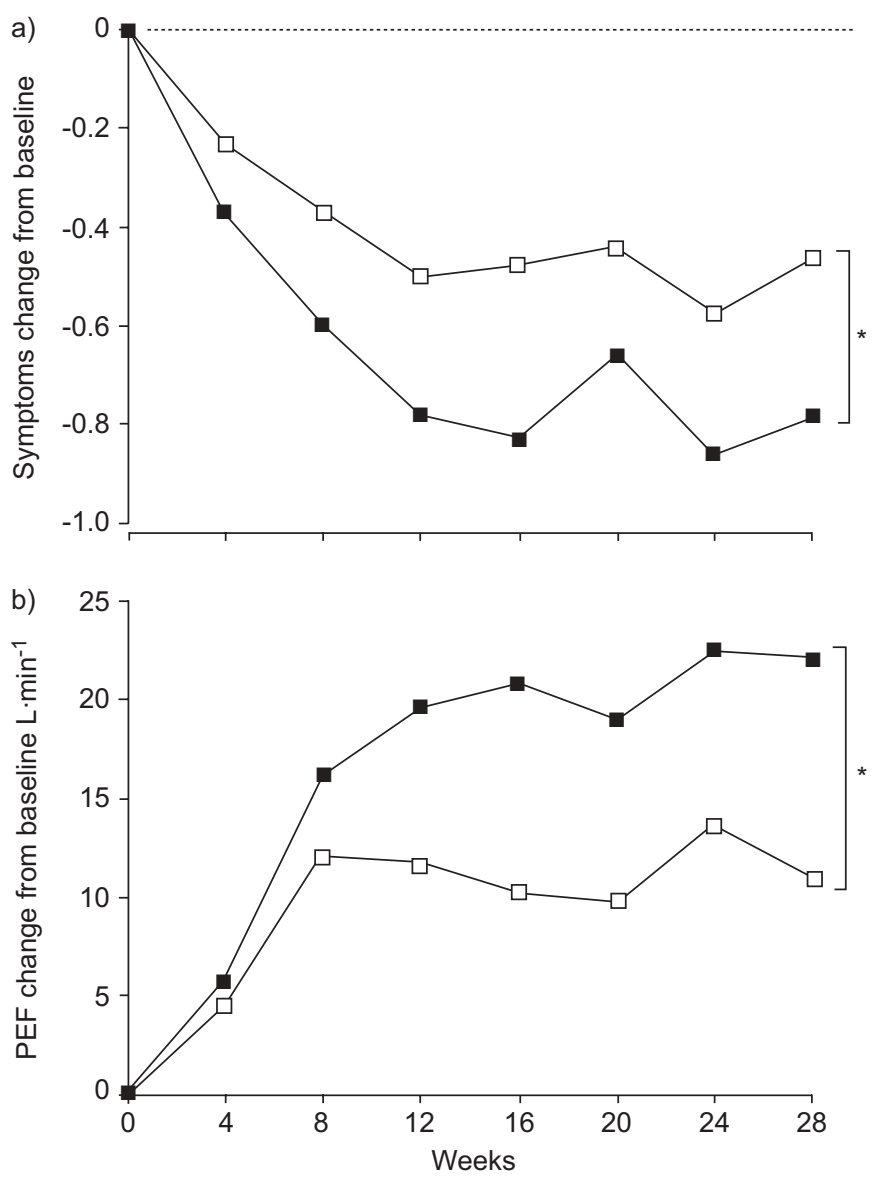

FIGURE 3. Changes in a) symptoms and b) peak expiratory flow (PEF) with time during omalizumab treatment. Changes from baselines are shown as leastsquares means. $\square$ : placebo; $\mathbf{\square}$ : omalizumab. ${ }^{*}: p<0.05$. Data taken from [1].

medication. Patient expectations of treatment should also be established. Regular medication needs to be continued or, if appropriate, reduced in a logical manner as agreed with the physician. Guidelines and requirements of local health authorities should be adopted.

\section{FUTURE DIRECTIONS}

Although the physician's overall assessment is an effective tool for assessing the response to omalizumab, further research is needed on predicting response. The development of an understanding of the differences in the immunopathology of the airways in omalizumab responder and nonresponder patients, and identification of a biochemical predictor of omalizumab response through examination of biomarkers in sputum and blood may provide clues to potential predictive factors valuable in optimising patient selection for omalizumab therapy.

\section{CONCLUSIONS}

When a patient with severe allergic asthma has symptoms that remain uncontrolled despite receiving high-dose inhaled corticosteroids along with a long-acting $\beta_{2}$-agonist, a trial of omalizumab is appropriate. Analyses of pre-treatment baseline variables as predictors of response to treatment have shown there is no reliable way to predict which patients within the label population will achieve a good response with omalizumab: all patients eligible for omalizumab treatment, based on their symptoms, should be trialled for 16 weeks and omalizumab treatment should be stopped or continued based on the physician's assessment of response at this time, as specified in the European Union label.

\section{REFERENCES}

1 Humbert M, Beasley R, Ayres J, et al. Benefits of omalizumab as add-on therapy in patients with severe persistent asthma who are inadequately controlled despite best available therapy (GINA 2002 step 4 treatment): INNOVATE. Allergy 2005; 60: 309-316.

2 Ayres JG, Higgins B, Chilvers ER, Ayre G, Blogg M, Fox H. Efficacy and tolerability of anti-immunoglobulin E therapy with omalizumab in patients with poorly controlled (moderate-to-severe) allergic asthma. Allergy 2004; 59: 701-708.

3 Vignola AM, Humbert M, Bousquet J, et al. Efficacy and tolerability of anti-immunoglobulin E therapy with omalizumab in patients with concomitant allergic asthma and persistent allergic rhinitis: SOLAR. Allergy 2004; 59: 709-717.

4 Busse W, Corren J, Lanier BQ, et al. Omalizumab, anti-IgE recombinant humanized monoclonal antibody, for the treatment of severe allergic asthma. J Allergy Clin Immunol 2001; 108: 184-190.

5 Lanier BQ, Corren J, Lumry W, Liu J, Fowler-Taylor A, Gupta N. Omalizumab is effective in the long-term control of severe allergic asthma. Ann Allergy Asthma Immunol 2003; 91: 154-159.

6 Solèr M, Matz J, Townley R, et al. The anti-IgE antibody omalizumab reduces exacerbations and steroid requirement in allergic asthmatics. Eur Respir J 2001; 18: 254-261.

7 Buhl R, Solèr M, Matz J, et al. Omalizumab provides longterm control in patients with moderate-to-severe allergic asthma. Eur Respir J 2002; 20: 73-78.

8 Holgate ST, Chuchalin AG, Hébert J, et al. Efficacy and safety of a recombinant anti-immunoglobulin E antibody (omalizumab) in severe allergic asthma. Clin Exp Allergy 2004; 34: 632-638.

9 Genentech, Inc. A multicenter, randomized, controlled, open-label study to evaluate the safety of $\mathrm{Xolair}^{\mathrm{TM}}$ in moderate to severe persistent asthma subjects already treated with other therapies (ALTO). http://clinicalstudyresults.gene.com/q2143g.pdf. Date last updated: November 2002. Date last accessed: May 2007.

10 Bousquet J, Cabrera P, Berkman N, et al. The effect of treatment with omalizumab, an anti-IgE antibody, on asthma exacerbations and emergency medical visits in patients with severe persistent asthma. Allergy 2005; 60: 302-308.

11 Bousquet J, Rabe K, Humbert M, et al. Predicting and evaluating response to omalizumab in patients with severe allergic asthma. Respir Med 2007; 101: 1483-1492.

12 Juniper EF, Guyatt GH, Epstein RS, Ferrie PJ, Jaeschke R, Hiller TK. Evaluation of impairment of health related quality of life in asthma: development of a questionnaire for use in clinical trials. Thorax 1992; 47: 76-83. 
13 Juniper EF, Guyatt GH, Willan A, Griffith LE. Determining a minimal important change in the disease-specific Quality of Life Questionnaire. J Clin Epidemiol 1994; 47: 81-87.

14 Lung function testing: selection of reference values and interpretative strategies. American Thoracic Society. Am Rev Respir Dis 1991; 144: 1202-1218.

15 Novartis AG, data on file.

16 MacGlashan DW, Bochner BS, Adelman DC, et al. Downregulation of FcERI expression on human basophils during in vivo treatment of atopic patients with anti-IgE antibody. J Immunol 1997; 158: 1438-1445.

17 Lin H, Boesel KM, Griffith DT, et al. Omalizumab rapidly decreases nasal allergic response and FceRI on basophils. $J$ Allergy Clin Immunol 2004; 113: 297-302.

18 Beck LA, Marcotte GV, MacGlashan D, Togias A, Saini S. Omalizumab-induced reductions in mast cell FceRI expression and function. J Allergy Clin Immunol 2004; 114: 527-530. 